\title{
Laboreal
}

Volume $8 \mathrm{~N}^{\circ} 1$ | 2012

Género, Atividades e Saúde

\section{Uma investigação pioneira em psicopedagogia experimental : introdução ao texto de Antoine Léon}

Una investigación pionera en psicopedagogía experimental : introducción al texto de Antoine Léon

Une recherche pionnière en psychopédagogie expérimentale : introduction au texte d'Antoine Léon

An innovative research on experimental psychopedagogy : introduction to

Antoine Léon's text

\section{Serge Blanchard}

Tradutor. João Viana Jorge

\section{CpenEdition}

\section{Journals}

\section{Edição electrónica}

URL: http://journals.openedition.org/laboreal/7408

DOI: $10.4000 /$ laboreal.7408

ISSN: 1646-5237

\section{Editora}

Universidade do Porto

Refêrencia eletrónica

Serge Blanchard, «Uma investigação pioneira em psicopedagogia experimental : introdução ao texto de Antoine Léon », Laboreal [Online], Volume 8 N$^{0} 1$ | 2012, posto online no dia 01 dezembro 2012, consultado o 24 setembro 2020. URL : http://journals.openedition.org/laboreal/7408 ; DOI : https:// doi.org/10.4000/laboreal.7408

Este documento foi criado de forma automática no dia 24 setembro 2020. 


\section{Uma investigação pioneira em psicopedagogia experimental : introdução ao texto de Antoine Léon}

Una investigación pionera en psicopedagogía experimental : introducción al texto de Antoine Léon

Une recherche pionnière en psychopédagogie expérimentale : introduction au texte d'Antoine Léon

An innovative research on experimental psychopedagogy : introduction to

Antoine Léon's text

\section{Serge Blanchard}

Tradução : João Viana Jorge

Em 1957, Antoine Léon, investigador no Service de Recherche de l'Institut National d'Etude du Travail et d'Orientation Professionnelle (INETOP), apresenta no boletim do Centre de Recherche Psychotechnique (CERP) então dirigido por Jean-Marie Faverge, uma pesquisa no terreno que incide sobre “os mecanismos de aquisição, no adolescente, dos primeiros elementos de um ofício » [1]. Esse artigo (1957a) relata um trabalho de pesquisa levado a cabo no Centre d'application de l'Ecole Normale Nationale d'Apprentissage (ENNA) de Paris onde se formam os professores técnicos dos Centres d'Apprentissages (CA), estabelecimentos que preparam em três anos, sob estatuto escolar, os (seus) alunos para a obtenção do certificado de aptidão profissional (CAP). Este texto insere-se no contexto da época. Nos anos cinquenta a França está ainda em pleno período de reconstrução, procura de operários e empregados qualificados é grande e a formação e orientação profissionais tornaram-se uma aposta nacional. Neste quadro, duas concepções sobre a orientação se opõem : por um lado a abordagem prognóstico-diagnóstico sustentada historicamente por Piéron (1949), director do INETOP, por outro uma concepção educativa e contínua representada por Antoine Léon (1957b). 
2 Esta oposição pode surpreender os leitores não franceses, especialistas das questões do trabalho. Em França, a orientação está historicamente ligada ao conhecimento do trabalho. Nos começos do século XX os primeiros trabalhos sobre orientação atribuemse o objectivo de regular a entrada dos mais jovens no ofício e o acesso à formação de todos os trabalhadores. Esta proximidade, reivindicada mas nem sempre assumida, permite compreender que hoje o INETOP, reagrupe, no seu centro de pesquisa, equipas de psicologia da orientação, de psicologia do trabalho, de ergonomia, de psicodinâmica do trabalho e de formação de adultos [2]. Nos alvores do século XX a degradação das formas de acesso ao ofício e das condições do trabalho operário faz da formação profissional dos jovens uma questão central. Nesse contexto, a ideia de orientação que começa a desenvolver-se responde à preocupação de dar aos jovens as colocações que correspondam melhor às suas aptidões em função das características próprias de cada ofício. A ideia de medir as características psicológicas com vista a organizar a distribuição dos indivíduos pelo mercado de trabalho não é nova mas a orientação confere-lhe, nos primeiros anos do século XX, uma nova forma de legitimidade científica considerando-a como uma aplicação da psicologia e dos seus instrumentos : os testes. Nesta vontade de classificação, o conceito de aptidão como disposição natural e a sua medida, são tidos como centrais (Ouvrier-Bonnaz, 2007).

\section{A orientação profissional em França nos anos 1950}

3 Em França, no decurso dos anos cinquenta, os conselheiros de orientação têm como tarefa principal a orientação profissional dos alunos que saiem da escola primária aos 14 anos e que desejam entrar em aprendizagem. 0 trabalho dos conselheiros consiste, no essencial, em verificar que os jovens apresentam o perfil de aptidóes requerido pelo exercício do ofício escolhido. 0 exame de orientação profissional tem por objectivo fornecer, aos jovens e suas famílias, que consultam um conselheiro, informações que podem ajudá-los na sua escolha de uma profissão, ou mais frequentemente, de uma formação profissional. Este exame de orientação profissional inclui provas escritas realizadas em sala de aula (sessão englobando testes de raciocínio, de abstracção, de compreensão técnica, de atenção, de memória, etc.), e uma consulta individual no Centre d'Orientation Professionnelle (com uma duração de cerca de 2 a 3 horas) que inclui a realização de provas de habilidade manual, de compreensão técnica, de velocidade de reaç̧ão ..., uma entrevista no decurso da qual o conselheiro procura detectar os interesses, os gostos, as aspirações profissionais do jovem e a sua intensidade, e também uma consulta médica de orientação por um médico de orientação profissional. 0 trabalho do conselheiro inscreve-se portanto numa démarche de diagnóstico das aptidões de um jovem tendo por objectivo estabelecer um prognóstico do seu sucesso na aprendizagem de uma profissão.

Notemos que, a par das tarefas de orientação, os conselheiros de orientação participam também em tarefas de selecção como a do recrutamento dos alunos dos estabelecimentos públicos do ensino técnico (centros de aprendizagem). Elaboram-se, pelo INETOP, baterias de testes com esta finalidade, desde 1948. Em 1952-1953 as consultas dos alunos no fim da escolaridade primária representam $62 \%$ da actividade dos conselheiros de orientação e as consultas respeitantes à entrada dos estabelecimentos de ensino técnico e escolas profissionais, 18 \% (Caroff, 1987, p. 148). 


\section{A concepção educativa de Léon em acção na sua psicopedagogia da orientação profissional}

É por oposição à démarche de diagnóstico-prognóstico que Léon desenvolveu uma concepção educativa da orientação profissional. Léon (1952c) critica uma concepção “ reveladora” da orientação profissional (utilização do método dos testes) para defender uma concepção " formadora ». Para Léon é a " noção de participação activa da criança na construção do seu futuro profissional que caracteriza a concepção educativa em matéria de orientação e de adaptação profissional. Esta concepção implica uma acção educativa contínua da parte do mestre, do conselheiro e dos pais na preparação da criança para a vida profissional. Apoia-se no carácter histórico, evolutivo das condutas individuais, na sua plasticidade e no papel decisivo desempenhado pelos meios formadores na sua elaboração. A adaptação profissional, longe de ser concebida em termos de ajustamento mecânico, resulta das formas sempre mais eficazes de condutas que o indivíduo põe em acção para resolver os problemas técnicos e sociais que se lhe colocam ao longo de toda a sua vida » (Léon, 1957b, pp. 12-13). É também necessário "fazer participar activamente os adolescentes na elaboração dos seus projectos, informá-los para que possam alargar o seu horizonte profissional e escolher o seu ofício de um modo mais reflectido, mais motivado » (Léon, 1957b, p. 55).

Léon está consciente dos limites da acção educativa. Sabe que a orientação profissional é fortemente influenciada pela origem social do indivíduo (cf. os resultados do inquérito do INED sobre A orientação e a selecção das crianças em idade escolar, conduzida em 1953 por Girard), pelas atitudes do jovem e da sua família face à escola. Langevin (1947) evoca assim “a impaciência em deixar a escola " frequentemente vivenciada pelo jovem. Não subestima o papel da cultura geral (concepção estreitamente utilitária da educação no meio parental) e o funcionamento do sistema escolar (organizado na época em duas grandes vias estanques, uma primária, a outra secundária) que orienta de modo precoce para uma formação profissional. Por isso inscreve a sua concepção educativa da orientação num projecto de mudança social (Léon faz referência ao plano Langevin-Wallon oriundo da Resistência, entregue em 1947 no gabinete da Assembleia Nacional e nunca discutido) que visa tornar o sistema educativo mais democrático e assim a sociedade mais justa.

\section{A concepção de Léon no que respeita à aprendizagem do ofício pelo adolescente}

7 Se bem que o estudo de Léon se focalize na questão dos " mecanismos de aquisição, no adolescente, dos primeiros elementos de um ofício ", ele interessou-se pelo conjunto dos problemas relevando da questão da aprendizagem do ofício pelo adolescente, questão que precisa " de responder a uma série de problemas que se estendem ao longo do período que decorre entre a escolha desse ofício e a colocação na produção " (Léon, 1954, p. 139) :

- Preparação da escolha profissional: com os seus colegas do INETOP (Bacquet, Cambon, Chaudagne \& Léon, 1957) Léon vai conceber e porá em prática sessões de informação sobre as profissões, recomendará avaliar os efeitos dessas sessões, nomeadamente "verificar como é que a informação modifica, na criança, a representação da vida profissional, como é que ela 
ecoa nas diversas condutas, sobre as suas opções profissionais, sobre a sua atitude face ao trabalho escolar » (Léon, 1957b, p. 66).

- Selecção à entrada dos estabelecimentos de ensino profissional : Léon (1957b) critica a noção de aptidão que dá proeminência aos factores inatos e que deixa portanto pouco espaço para a possibilidade de intervenções educativas; critica também os testes que fornecem uma avaliação global do funcionamento intelectual mas que não trazem senão muito pouca informação sobre os mecanismos psicológicos postos em acção pelo jovem; critica igualmente uma concepção estática da adaptação jovem-emprego enquanto que o jovem e os empregos evoluirão ; sublinha enfim a fraca participação do jovem na elaboração dos seus projectos profissionais no quadro da démarche prognóstico-diagnóstico.

- Escolhas profissionais (Léon, 1952a, 1953b) : Léon interessa-se pelos factores que influenciam as escolhas profissionais dos adolescentes, como o conteúdo da informação a dar aos adolescentes (informação dos aprendizes sobre as perspectivas de futuro dos ofícios) e as actividades de pré-aprendizagem de alguns ofícios que permitem ter em conta as performances alcançadas pelos adolescentes no decurso de diferentes estádios da iniciação profissional. Segundo ele, “ a negação ou pelo menos o negligenciar da importância da função educativa na formação dos gostos e das aptidões profissionais conduz o psicólogo a orientar a sua actividade para a detecção do que é suposto ser permanente no indivíduo mais do que para a transformação do que é o fruto transitório de uma série de interacções entre o mesmo indivíduo e o seu meio. A atitude teórica subjacente ao controlo de previsões com base no empirismo estatístico tende a limitar as relações da orientação profissional e da escola a simples trocas de resultados psicotécnicos ou escolares ». Léon pensa que "o conselheiro deveria sobretudo (...) participar directamente no processo de formação da criança ou do adolescente no quadro do ensino primário e do ensino profissional » (Léon, 1953b, p. 213).

- Inadaptação à aprendizagem (Léon, 1953a) : Léon coloca a tónica nas condições de inadaptação inerentes à vida do estabelecimento escolar. Para ele, “o conhecimento dessas condições permite pôr o problema da inadaptação mais em termos de formação do que em termos de selecção, mais em termos de recuperação do que em termos de deficiências consideradas como imutáveis. Acrescenta, simultaneamente, as possibilidades de acção do orientador e do educador » (Léon, 1954, p. 150). Léon interessa-se também pelas condições pedagógicas e sociais susceptíveis de reforçar a motivação para a aprendizagem profissional. Se o interesse pelo ofício aprendido aumenta entre o primeiro e o terceiro ano do CAP, isso " não se liga somente a uma espécie de resignação passiva ou a uma tomada de consciência, pelo adolescente, da impossibilidade de mudar de ofício. Liga-se sobretudo à criação de interesses novos no próprio decurso da aprendizagem do ofício... A evolução das motivações profissionais do adolescente é condicionada pela elaboração de uma representação cada vez mais rica e mais objectiva das condições objectivas do ofício aprendido » (Léon, 1957b, pp. 43-44).

- Docimologia dos exames profissionais: Léon (1952b) assinala que "a instituição de exames concebidos como meio de controlo dos conhecimentos adquiridos com vista a uma dada formação, aparece hoje como legítima e até indispensável (...) As regras docimológicas não podem ganhar todo o sentido senão no quadro de reformas importantes reportando-se respectivamente à preparação dos candidatos, à elaboração das provas e ao papel dos examinadores » .

8 É o ter em conta o conjunto destes factores que pode contribuir para o desenvolvimento de uma psicopedagogia da orientação na visão educativa (Léon, 1957b). 


\section{Os mecanismos de aquisição, no adolescente, dos primeiros elementos de um ofício}

9 Na sua " análise de alguns mecanismos de aquisição, no adolescente, dos primeiros elementos de um ofício », Léon, em colaboração com Dacquin, um professor do ensino técnico, tenta pôr em acção a sua concepção da orientação numa pesquisa no terreno incidindo num grupo de 25 aprendizes de 15-16 anos que já tinham frequentado um primeiro ano de formação em montagem de máquinas e que, no início do seu segundo ano frequentam um estágio de iniciação na fresagem que se estende por um período de uma semana envolvendo 18 horas de oficina.

Os aprendizes trabalham em grupos de quatro o que permite observar as suas condutas individuais de aprendizagem e nomeadamente assinalar as suas dificuldades e erros. Para compreender os erros, os aprendizes são questionados seja directamente perante a sua máquina seja no decurso de uma entrevista incidindo num exercício de controlo. Apoiando-se nas análises de Pacaud (1955), Léon põe a hipótese de que certos erros estariam ligados a um processo de generalização apressada e, para verificar essa hipótese os aprendizes são convidados a explicar e justificar por si próprios tal ou tal acto profissional particularmente difícil.

11 Os grupos são submetidos a dois métodos educativos diferentes : um método qualificado de global-intuitivo e um outro no decurso do qual os aprendizes são convidados a fazer um esforço de análise e de utilização de conhecimentos gerais na fase preparatória do trabalho propriamente dito sobre a máquina. Apoiando-se nos resultados deste estudo, Léon defende o interesse e a legitimidade da pesquisa psicopedagógica no domínio dos ensinos técnico e geral, pesquisa em que prosseguirá ao longo de toda a sua carreira (Léon, 1977).

\section{Que prolongamentos deste tipo de pesquisa?}

Em desacordo com o seu director, H. Pieron (1952), Léon (1991, p. 94) abandonará o INETOP onde pesquisas psicopedagógicas serão conduzidas e publicadas muito mais tarde, por exemplo sobre a natureza e o desenvolvimento do raciocínio matemático do $3^{\circ}$ ao $9^{\circ}$ ano de escolaridade por Pelnard em 1976, sobre a compreensão da leitura entre o $6^{\circ}$ ano e o $9^{\circ}$ ano de escolaridade por Pelnard em 1981 e por Aubret em 1991, sobre a condução das máquinas-ferramenta por Lemercier em 1981, sobre o raciocínio técnico por Gillet de 1979 a 1986, sobre a resolução de problemas de física por Rozencwag e Trosseille em1996, sobre a educabilidade cognitiva por Loarer em 1991. Respeitante a este último sector de pesquisa trata-se ainda de encontrar soluções para os problemas de adaptação com que os profissionais pouco qualificados se deparam na sua actividade, face às mutações tecnológicas e de auxiliar a inserção de populações de baixa escolaridade.

13 Ao contrário de Léon, os conselheiros de orientação investiram pouco no campo da psicopedagogia do ensino geral - salvo no domínio de despistagem e análise das dificuldades na leitura na entrada do $6^{0}$ ano de escolaridade (Aubret, Blanchard \& Sontag, 2006) - e técnico talvez por que a influência das pesquisas psicopedagógicas sobre a formação dos docentes e suas práticas se mantêm actualmente ainda muito débeis. É também, provavelmente porque os trabalhos de Léon tiveram pouco eco nos 
meios da orientação. Em França, numa altura em que a abordagem educativa da orientação se instala de forma duradoura na Escola, a contribuição de Léon deveria ser ainda útil. Mais geralmente, além da especificidade francesa, num mundo em que o trabalho real é cada vez mais difícil de ver e descrever e portanto a ter em conta para ajudar os jovens a melhor se situarem no mundo profissional, os trabalhos precursores de Léon deveriam ser úteis a todos aqueles que se interessam pela ligação a (re)construir entre o trabalho e a sua análise e a orientação escolar e profissional.

\section{BIBLIOGRAFIA}

Aubret, J., Blanchard, S., \& Sontag, J.-C. (2006). Évaluer les compétences en lecture des collégiens en $6^{\mathrm{e}} / 5^{\mathrm{e}}$. L'orientation scolaire et professionnelle,35,3, 446-473.

Bacquet, R., Cambon, J., Chaudagne, H., \& Léon, A. (1957). Pour l'information professionnelle des jeunes gens de 14 ans. Paris : Ed. Bourrelier.

Caroff, A. (1987). L'organisation de l'orientation des jeunes en France : évolution des origines à nos jours. Issy-les-Moulineaux, EAP.

Langevin, P. (1947). Numéro spécial : Paul Langevin, écrits philosophiques et pédagogiques. Pour l'Ere Nouvelle, mars-avril.

Léon, A. (1952a). Le choix professionnel des candidats aux centres d'apprentissage. BINOP, numéro spécial.

Léon, A. (1952b). Le rôle des examens. Bulletin de psychologie, numéro spécial, 31-40.

Léon, A. (1952c). Problèmes théoriques et pratiques de l'orientation professionnelle. La Raison, 4, 122-148.

Léon, A. (1953a). Contribution à l'étude de l'adaptation à l'apprentissage. Enfance, 1, 75-83.

Léon, A. (1953b). Variations des choix professionnels. BINOP, 5, 204-217.

Léon, A. (1954). Quelques aspects de l'apprentissage du métier chez l'adolescent. L'Année Psychologique, 54, 1, 139-156.

Léon, A. (1957a). Analyse de quelques mécanismes d'acquisition des premiers éléments d'un métier chez l'adolescent. Bulletin du CERP, 2, 183-188.

Léon, A. (1957b). Psychopédagogie de l'orientation professionnelle (préface de Henri Wallon). Paris : PUF.

Léon, A. (1977) (Dir.). Manuel de psychopédagogie expérimentale. Paris : PUF.

Léon, A. (1991). Note sur l'histoire de l'orientation professionnelle en France. Histoire de L'Education, 49, 89-98.

Ouvrier-Bonnaz, R. (2007). A psicologia em França de 1870 a 1940, de uma ciência aplicada a uma disciplina universitária, Laboreal, 3 (1), 57-63. http://laboreal.up.pt/revista/artigo.php 
Pacaud, S. (1955). Méthode normative et méthode expérimentale en psychologie du travail. Journal de Psychologie Normale et Pathologique, 52.

Piéron, H. (1949). La psychologie différentielle. Paris : PUF.

Piéron, H. (1952). Le rôle d'un conseiller ne doit pas se confondre avec celui d'un éducateur. BINOP, numéro spécial.

\section{NOTAS}

1. Jean-Marie Faverge que acabara de publicar com Ombredane, “L'analyse du travail » (1955) encontrou múltiplas semelhanças entre os trabalhos conduzidos no CERP e os de Léon (considerações recolhidas junto de Jacques Leplat que sucederia a Faverge na direcção do CERP).

2. O Groupe de Recherche et d'Etude sur L'Histoire du Travail et de l'orientation (GRESHTO), grupo transversal do conjunto dessas equipas atribui-se o objectivo de pensar conjuntamente a história do trabalho e da orientação.

\section{AUTORES}

\section{SERGE BLANCHARD}

Groupe de Recherche et d'Etude sur l'Histoire du Travail et de l'Orientation (GRESHTO), Centre de Recherche sur le Travail et le Développement (CRTD), Conservatoire National des Arts et Métiers (CNAM), 41, Rue Gay Lussac 75005, Paris, France

blanchard.serge@wanadoo.fr 